\title{
IS Strategic Decision-Making: A Garbage Can View
}

\author{
Harald Fardal \\ Vestfold University College, \\ Horten, Norway
}

Harald.Fardal@hive.no

\author{
Jan Oddvar Sornes \\ Bodø Graduate School of \\ Business, Bodø, Norway
}

Jan.Oddvar.Soernes@hibo.no

\begin{abstract}
Developing information systems (IS) strategies and choosing the right IS portfolio for an organization require, among other things, identifying the most appropriate IS projects, determining how best to organize the IS staff, and arranging for IS procurement. All of these actions involve decision-making. This paper analyzes IS strategic decision-making in organizations, with the Garbage Can Model (GCM) of decision-making providing the theoretical framework. Our findings show that IS strategic decision-making often happens through GCM processes, and while these processes are hard to control and predict, the decision quality tends to be high at the organizational level. At the individual level, however, Garbage Can processes tend to return low-quality IS strategic decisions.
\end{abstract}

Keywords: IS strategy, IS strategic decision-making, Garbage Can Model (GCM)

\section{Introduction}

Developing information systems (IS) strategies and choosing the right IS portfolio for an organization -involve decision-making, such as identifying the right IS projects, deciding how best to organize the IS staff, and specifying IS procurement. Although Strategic Information Systems Planning (SISP) has received growing attention from both scholars and practitioners, especially with regard to decision-making, an organization's perennial challenge is to make the right decisions, one reason being the highly dynamic and emergent nature of technologies and organizational forms. To date, research has focused on finding the optimal IS strategy development processes for organizations (Basu, Hartono, Lederer, \& Sethi, 2002; Gottschalk, 1998, 1999; Salmela $\&$ Spil, 2002; Teubner, 2007). But organizations can be very dissimilar, owing to underlying differences in their structures and actors, so the same processes cannot be rotely implemented for everyone and in any case. Complicating the picture even further, decision-making occurs at different levels and at different times in different organizations. This paper therefore addresses IS

Material published as part of this publication, either on-line or in print, is copyrighted by the Informing Science Institute. Permission to make digital or paper copy of part or all of these works for personal or classroom use is granted without fee provided that the copies are not made or distributed for profit or commercial advantage AND that copies 1) bear this notice in full and 2) give the full citation on the first page. It is permissible to abstract these works so long as credit is given. To copy in all other cases or to republish or to post on a server or to redistribute to lists requires specific permission and payment of a fee. Contact Publisher@InformingScience.org to request redistribution permission. strategic decision-making in organizations known as "organized anarchies," (Cohen, March, \& Olsen, 1972) and views the IS strategy-development processes as a set of decisions. "Organized anarchies" bear that name because of their three common attributes: fluid participation, problematic goals, and unclear technology. The Garbage Can Model (GCM) of decision-making (Cohen et al., 1972) serves as the theo- 
retical framework for the analysis as it is particularly suited for understanding decision-making in organized anarchies.

Organizations make IS strategic decisions to increase organizational performance. But the effectiveness of those decisions hinges on how purposefully the employees use the ISs. Fardal (2007) found that when both IS users and the managers responsible for the IS strategic processes agree as to the correct IS strategic choices, it has a positive influence on the IS use. IS use is even further enhanced if the users are directly involved in IS strategic processes, including decision-making. This underlines the importance of studying IS strategic decision-making, as the quality of IS use directly affects organizational performance (Henry \& Stone, 1995). Furthermore, research shows that many organizations find it a struggle to actually implement their IS strategy (Gottschalk, 2002). Some of this failure no doubt stems from poor decisions at the very heart of that strategy. The present study adds to existing knowledge in this domain as organizations must be able to make IS strategic decisions that reflect their needs, prove economically realistic, and align with their business strategies (Ba, Stallaert, \& Whinston, 2001; Fardal, 2007; Henderson \& Venkatraman, 1993, 1999; Teubner, 2006). Consequently, processes concerning both development and implementation of IS strategy need to be improved to avoid failure.

Several studies have proposed alternative approaches for IS strategy planning and development (e.g. Earl, 1993; Levy, Powell, \& Galliers, 1999; Newkirk \& Lederer, 2007; Salmela \& Spil, 2002; Teubner, 2007). Earl (1993), for instance, found that companies might use one or more of five different approaches to SISP: Business-Led, Method-Driven, Administrative, Technological, and Organizational. Earl concluded that an Organizational approach seemed the most effective; however, he suggested that hybrids, mixing elements from several approaches, might be even more effective. Salmela and Spil (2002) propose the four-cycle model, which provides a basic schedule for planning activities. The model combines the strengths of both comprehensive and incremental planning. Their initial action research indicates that it should be used as a choice list in the planning process. Finally, in a new survey study, Newkirk and Lederer (2007) found that heterogeneity and hostility influence the planning process and conclude that these dimensions of environmental uncertainty should consider planning more carefully.

Henderson and Venkatraman (1999) highlight the importance of an organization's aligning its IS strategy with its business strategy. Their findings indicate that strategic alignment gives a firm better performance and more efficient IS use. However, they don't discuss how strategic alignment might be achieved, perhaps assuming that different organizations will surely require different processes to achieve it. Reich and Benbasat (2000) criticize the pure organizational focus of Henderson and Venkatraman. After investigating the social dimension of strategic alignment, they conclude that the individual level should be included when studying IS strategic phenomena. $\mathrm{Ba}$, Stallaert, and Winston (2001), meanwhile, argue that alignment and IS development research need to focus more on user incentives and to recognize that users' objectives often differ from organizational objectives. They introduce a new dimension to alignment between business objectives and IS. They call it "incentive alignment." According to Ba et al., any IS strategy process must focus on developing incentives of who, when and how to use a given IS.

As shown above, considerable research has been conducted in regard to IS planning and strategy development. However, little research has focused on how organizational decision-making influences the IS strategic processes. Undoubtedly, any strategic-planning process involves numerous decisions, so it's no less important to investigate the decision-making process itself. This study explores IS strategic decision-making in the Norwegian entrepreneur business. The organizations studied here have similarities to Cohen et al.'s (1972) description of an organizational anarchy, thus inspiring us to use their Garbage Can Model as our analytical framework. 


\section{The Garbage Can}

The Garbage Can Model of organizational choice, first developed by Cohen et al. (1972), describes decision-making in organizational anarchies. Their model has since been revised by March and Olsen (March \& Olsen, 1984; March, Olsen, \& Christensen, 1976). The GCM provides a decision-making framework that helps us understand how new ideas might diffuse. In the GCM, solutions-i.e., new ideas-often look for problems to solve, so the model is particularly good at explaining the diffusion of new ideas in often randomized processes (Cohen et al., 1972; Kanter, 1988). Organizations typically have individuals tasked with promoting those solutions (Crecine, 1986). The GCM has been widely applied because GCM conditions fit the wellaccepted concept of "bounded rationality," a concept that addresses why decision-makers can be only somewhat rational about their choices. Given the considerable uncertainty they face, such as changing markets, and given, too, the constantly changing technologies they must quickly try to adapt to, there are limits as to what they can predict and control. So they must constantly interpret (make sense of) their actions at the very same time as they do them, and they must also try to per-

suade one another of the viability and legitimacy of those actions (Browning, Sørnes, Stephens, \& Sætre, 2006). In the 1972 study by Cohen et al., universities provided the reference of such organizations, but in fact all organizations that fit the characteristics can be categorized as organizational or structural anarchies. According to Cohen and March (1974), the Garbage Can involves three initial conditions:

- Problematic goals. These are defined as "inconsistent and ill-defined preferences" (Cohen et al., 1972, p. 1). Because decision-makers often disagree about their organization's goals, it's difficult for them to act on those goals in concert. Compounding matters, individual decision-makers will often rethink their own preferences over time, even though preferences are expected to be stable (March and Olsen, 1984). In fact, preferences are notably unstable because organizational goals have a habit of changing, either from failure or from success (Browning et al., 2006).

- Unclear technology. Even on those rare occasions when decision-makers all agree on their organization's goals, they still confront the challenge of "unclear technology" (Cohen et al., 1972, p. 1). That is, the preferred technology to accomplish these goals is often unknowable. Because organizational members generally act under conditions of at least partial uncertainty, their day-to-day actions are in fact a "practice" much the same as medicine is commonly called a "practice"-that is, one must often proceed experimentally, speculatively, acting before knowledge of the results is fully certain: "Participants arrive at an interpretation of what they are doing and what they have done while in the process of doing it" (Cohen et al., 1972, p. 2).

- Fluid participation. Organizational members often change jobs, be it within departments or between firms. Even among stable units, participants will vary in how much time and effort they give to different organizational problems. Given all this "fluid participation" (Cohen et al., 1972, p. 1), some members of the organization may be even less involved than outsiders. Being the most prominent characteristic of our entrepreneur companies, fluid participation in the studied contexts expresses itself chiefly through the random composition of IS projects.

According to GCM, these three conditions structure the reality of organizational life. Whereas Weber's (1947) traditional model postulates rationality, the GCM postulates just the opposite: lots of messy processes, unstructured relationships, contested goals, and uncertain results. And it emphasizes the instability within every organization - new things are constantly getting added, with old things getting dumped out. These three conditions of organizational life create four "streams of variables" (Cohen et al., 1972, p. 3) that we will analyze here in relation to IS strat- 
egy: problems, solutions, participants, and choice opportunities. A word now about these four factors.

\section{Four Streams of Variables}

Problems: Problems are the concerns of people, both inside and outside the organization, that require attention (Crecine, 1986). The term "problems" is primary for GCM because so much of organizational life focuses on problem-solving. A common theme in problem-solving is allocating ownership of the problem, because the owner will be chiefly responsible for taking action to solve it, while others may give it only marginal attention. Just as there is a division of labor, there is a division of "problems" to be sorted and assigned for action (Browning et al., 2006).

Solutions: Solutions are answers actively looking for questions. This notion may be the most original component of GCM, because it reverses the traditional wisdom of the problem-solution relationship. Instead of viewing individuals in organizations as problem-solvers, it views them as solution-marketers. A solution is somebody's product, be it a new consumer product or a new process for performing some work routine (Browning et al., 2006). From this point of view, a new IS is not merely a solution to a problem but a source of identity to its originator, who will keep marketing that same product in new places by "actively looking for a problem to which it is a solution" (Crecine, 1986, p. 84). GCM makes "offering solutions" a key organizational action and suggests such an orientation is ingrained because most people aspire to progress, to "move ahead." An organization is "a collection of choices looking for problems, issues and feelings looking for issues to which they might be an answer, and decision-makers looking for work" (Cohen et al., 1972, p. 2).

Participants: Participants bring different amounts of attention to their organizations, and how best to manage that attention is each individual's task. First, of course, they simply "come and go" (Cohen et al., 1972, p. 3). But they also have limited concentration as well as varying interest in the multiple tasks they face, so they must choose to allocate their attention based on how much time they have to participate: "Participation in a particular choice situation is constrained by other demands on a participant's time and attention" (Crecine, 1986, p. 85). GCM uses "participants" as a way of capturing organizational membership because it focuses on the varying degree of investment that members have in their work. Cohen et al.'s (1972) use of the term "participants" appears quite shrewd. Calling them "agents" would have emphasized their organizational ties and their responsibility to represent the organization (Eisenhardt, 1989b). Calling them "players" would have emphasized the negotiated order and the politics of organizational life (Strauss, 1978). Calling them "social actors" would have emphasized their networks and the way they represent their IS competence in a changing world (Lamb \& Kling, 2003). But the term "participants" focuses on their investment in the work environment and how willing they are to be involved in what is going on. A GCM position that helps us properly understand the term "participants" is its emphasis on the role of choosing, which focuses on people moving toward what they prefer, as opposed to deciding, which eliminates options until only one possibility remains. "Participation" implies that an individual freely chooses whether to be involved in the various tasks at hand (Browning et al.).

Choice opportunities: Choice opportunities are occasions when an organization is expected to produce a decision: "People must be hired, promoted, or fired; money spent; and responsibilities allocated" (Cohen et al., 1972, p. 3). These examples of hiring and promoting imply a hierarchy, or power structure, that allocates resources and legitimizes making choices.

Accepting these four conditions of organizational reality makes it possible to view ISs in GCM terms. Its emphases on individual involvement (participation), how an IS is used (solutions), what the technology is directed toward (problems), and how much freedom an individual has to make 
decisions (choice opportunities) make this model especially useful for understanding IS strategy development and implementation under conditions of uncertainty.

Cohen et al. (1972) consider two aspects of organizational structure: access structure and decision structure. Access structure describes how problems are mapped to choices, while decision structure describes mapping of choices onto decision-makers. Combined with the total amount of attention these problems receive from the participants, these structures affect how and if problems are solved.

The GC model has received considerable attention, and several studies have empirically verified it, or parts of it (P. A. Anderson \& Fischer, 1986; Levitt \& Nass, 1989; Lipson, 2007; Masuch \& Lapotin, 1989; Padgett, 1980; Waguespack, 2006; Weiner, 1976). Levitt and Nass applied it to the domain of textbook publishing and found that although GCM processes dominate editors' decision-making, institutional mechanisms affect decisions. In a more recent study, Waguespack (2006) studied organizational decisions in environmental- hazard management and found that problem complexity and importance influence the degree to which GCM processes affect decisions. Problems of high or low importance will be less influenced by GCM processes than problems of medium importance. Problems of low importance/complexity are so easy to solve that decisions are made on experience and without much effort, while problems of high importance/complexity require so much attention that means-ends rationality forms the basis of the decision-making. The above-mentioned studies use different methodological approaches to apply the GCM to the various domains. Some (e.g. P. A. Anderson \& Fischer, 1986; Masuch \& Lapotin, 1989) have been faithful to or extended the computer-simulation model in the original paper by Cohen et al. (1972). Others have applied qualitative case or field studies (e.g. Magjuka, 1988; J.G. March \& Weissinger-Baylon, 1986; Waguespack, 2006; Weiner, 1976). The richness of the GCM allows for this variation in methodological approach, but it also signals that concept definitions may be weak, so researchers must define and adjust the concept to fit their particular approach and domain of research. Eisenhardt and Zbaracki (1992) label most of this research merely descriptive and claim limited normative contributions from it. Hence this charge remains a challenge in GCM research.

\section{Garbage Cans and IS Strategic Decision-Making}

As the previous section shows, the GCM has proven its applicability in other research domains. Although some studies of GCM processes have been conducted within the IS domain (e.g. Boynton \& Zmud, 1987; Hayes \& McGee, 1998; Lovata, 1987; Travica \& Cronin, 1995; Watson, 1990), further investigation of how GCM processes affect IS strategic decision-making is needed. The pace at which technology develops makes successful IS strategic decision-making a truly daunting task. Development of new technology introduces not only new solutions to existing problems but also new problems. Consider, too, the density of highly competent knowledge workers who not only are capable of contributing in IS strategic decision-making (Fardal, 2007) but who actually insist on participating in it. They clearly provide a rich environment for GCM processes. This study investigates the nature of these processes and the quality of the IS strategic decisions made. Therefore, it aims to extend the existing knowledge frame within IS strategy research and provide normative contributions. The next section, on methodology, describes the procedures we undertook to accomplish this.

\section{Methodology}

Unlike Cohen et al. (1972), who used a computer-simulation model to identify how decisions are made in an organized anarchy, this paper utilizes qualitative methods to approach the research objectives. The inductive nature of the research objectives, plus our using the GCM to better un- 
derstand IS strategy decision-making, represents a new approach, and makes qualitative methods appropriate (e.g. Golden-Biddle \& Locke, 1997; Locke, 2001; Stenbacka, 2001). The methodological approach produces the challenge of mapping the qualitative data to Garbage Can processes and identifying decisions as a result of such processes. The procedures we applied to handle this challenge are described in detail in the data-analysis section. The rest of the present section will discuss the research site and participants, and then present the data analysis. The last section will present our findings.

\section{Research Domain and Participants}

We targeted Norwegian entrepreneurs as our research domain for two reasons. First, they have a strong focus on their core business, namely the construction of buildings, roads, bridges, and so forth. Second, the entrepreneur business in Norway currently experiences a very busy times. Studying IS strategy processes in environments with an intense focus on core activities and with a very high activity level is interesting in itself, and will provide useful insight in the leverage of IS and IT under these conditions. We chose, as research objects, four organizations, all of them operating in different entrepreneurial segments. One of the organizations primarily delivers consultant services to entrepreneurs. Two of them construct and maintain roads, including bridges and tunnels; and one of these two is also involved in planning Norway's road infrastructure. The fourth organization is a corporation with several divisions, operating throughout Scandinavia that performs whatever entrepreneurial tasks their particular market demands. These divisions differ in size, ranging from some 200 to 6,000 employees; however, all of them are dispersed to multiple geographical locations, and all are characterized by a high degree of personal and divisional freedom that may produce some challenges in IS strategic development. Mintzberg and McHugh (1985) use the witty term adhocracy to describe The National Film Board of Canada, and the firms in our own study certainly fit an "adhocracy lite" description. In an adhocracy, the different parts of an organization are loosely coupled, making its formal structures hard to identify. It presents managers the challenge of keeping continuously atop the organization's varied activities. Cohen et al.'s. (1972) organizational anarchy shares some similarities with Mintzberg and McHugh's adhocracy, but they are not the same. An organizational anarchy may be surrounded by formal structures; however, the decision-making processes don't resemble these structures. One may find Cohen et al.'s organizational anarchies within adhocracies, but also in organizations with seemingly more formal structures. In our own study, the organizations can be viewed as organizational anarchies within a lite adhocratic structure.

\section{Sampling procedure}

Our study used the theoretical sampling procedures laid out by Strauss and Corbin $(1990 ; 1994)$ for doing qualitative analysis. The targeted interviewees in this project had been employed in the organization for at least three years, and depended on IS-systems in their everyday work. The rationale is that people need to be part of an organization for some time to experience the IS strategic processes and thus be able to fairly evaluate them. The interviewees had experience in using relevant information systems in their respective organizations, because it is likely that IS-strategic considerations have been done while using these systems. We consider data from clerks to be just as valuable as data from managers or leaders in this context. In addition, we interviewed at least one person in each organization who was responsible for the IS strategic processes (usually the $\mathrm{CIO}$ ). Data from this interview provides the IS management of the decision-making processes in IS strategy development.

Our sampling procedure was a combination of narrow and wide sampling (Cutcliffe, 2000). A narrow sample consists of participants with lots of experience within the area of interest. Sup- 
porters of such a sample argue that one cannot comment on the studied processes if one doesn't share the same experiences (Resnik Mellion \& Moran Tovin, 2002). In a wide sample, on the other hand, the participants may have diverse backgrounds and experience. Supporters of wide sampling argue that it lets them capture data with maximum variety (Resnik Mellion \& Moran Tovin, 2002). We used wide sampling here because we wanted to allow our participants to come from different levels and divisions in their organization. But we also narrowed our sample by including only participants with a certain experience who use a strategically important IS. This sampling process of selecting participants for their differences as well as their similarities fits with the sampling procedures proposed by Glaser and Strauss (1967) and Sørnes (2004).

\section{Data Collection}

Data was collected using semi-structured in-depth interviews. This method allows for adaption to each individual and to the context. Although the field was not entered without prior conceptions, ideas, and knowledge with respect to the area investigated, the semi-structured interviews provided a fine balance between necessary subjects and respondents' initiatives and provided our study with relevant data and a manageable direction (Strauss \& Corbin, 1990).

Interviewing people in their natural environment poses a few challenges for the researcher, as one has to adapt to the degree of openness in the organization. Lofland and Lofland (1994) view organizations as non-public closed settings, and this highlights two possible areas of caution. First, the researcher's behavior may affect the reliability and quality of the respondents' answers during interviews. Second, the lack of openness among the subjects could affect the quality of the collected data. We attempted to meet these challenges by formulating and addressing our questions in an understandable manner and by paying attention to the communicational artifacts in the organizations, resulting in what we deemed successful adaptation to them.

This study followed an interview guide based on Spradley's (1979) "grand tour guide," and data collection took place over a period of five months-from December 2006 to April 2007. Following Spradley's principles, our questions encouraged the respondents to tell their story-in this context, about IS strategy processes and decisions in their respective organizations. To further ensure richness, the participants were first informed about the study and were given time to settle into the situation. Our initial questions merely served as warm-ups-a means of familiarizing the participants with the interview setting.

Eighteen interviews were conducted, mostly with employees from different levels in the organizations, including the CIO. Each interview lasted for 40-75 minutes and was audio-recorded. When transcribed, the recordings yielded a total of 180 pages of single-spaced text.

\section{Data Analysis}

For our study, we employed QSR Nvivo 7, a popular tool for organizing qualitative data, and then subjected our data to a grounded-theory analysis (Glaser \& Strauss, 1967). We also performed a subsequent analysis in order to map the original four GCM components to the grounded-theory categories. Owing to the sheer volume of our raw data, we followed the coding procedures described by Glaser and Strauss, and used constant comparative analysis because it enables researchers to revise and modify their analysis as further data are gathered (Glaser, 1998; Glaser \& Strauss, 1967). The procedures consisted of two main steps: (1) incident identification and (2) categorization. It's important to emphasize that these analytical steps, including data collection, are iterative. During the first step, incidents consisting of single sentences or short paragraphs were marked and labeled. The open-coding, or incident-identification, process resulted in 764 single codes. Through an iterative coding-axial-coding - process this was reduced to 14 main 
categories, and these categories ultimately organized all the raw data used in this study. Table 1 provides an overview of the categories and how they map to the Garbage Can variables.

Table 1: An overview of the Grounded Theory categories and how they map to the Garbage Can variables.

\begin{tabular}{|c|c|c|}
\hline Grounded Theory categories & & Garbage Can variables \\
\hline $\begin{array}{ll}- & \text { Organizational needs } \\
\text { - } & \text { Degree of formalized com- } \\
\text { munication }\end{array}$ & Maps to & Stream of problems \\
\hline $\begin{array}{ll}\text { - } & \text { Knowledge of IS strategy } \\
\text { - } & \text { Future }\end{array}$ & Maps to & Stream of solutions \\
\hline $\begin{array}{ll}\text { - } & \text { Strategic process } \\
\text { - } & \text { Strategically important }\end{array}$ & Maps to & Stream of choice opportunities \\
\hline $\begin{array}{ll}\text { - } & \text { Management commitment } \\
\text { - } & \text { User commitment } \\
\text { - } & \text { User Initiatives } \\
\text { - } & \text { User participation } \\
\text { - } & \text { Training } \\
\text { - } & \text { Perceived competence }\end{array}$ & Maps to & Stream of participants \\
\hline
\end{tabular}

Because Glaser and Strauss's different approaches to grounded theory enhance different parts of the analyzing process (Charmaz, 2000), we chose to utilize elements from both. Glaser's approach focuses on developing models and concepts from data, so we used his version when generating the 14 categories from data from the 764 single codes and generating properties from the categories. The focus on tapping the "latent structure" from the single codes into overarching categories has been valuable advice in this study. Strauss's philosophy of grounded theory encourages more of a connection to previous concepts by sorting them by to which degree they affirm existing research findings and theory or by whether the concepts require a novel conceptualization because no previous theory explains them. He recommends using existing to add more social science meaning to the data. We take a middle position on the grounded theory debate in this paper. Our 14 categories arise from the interview data with no previous theories attached to them, just as Glaser urges. Following Strauss's direction, we then applied the existing GCM to the data set.

\section{Mapping GT categories to GCM variables}

We applied the grounded-theory results to the GCM streams of variables by analyzing the 14 categories and determining whether each could be included in one of the four GCM variables. In this process we acknowledged that the single data pieces can be interpreted in more than one way, following the principles of grounded theory (Browning et al.). To determine which GCM category best fit each of our grounded-theory data, we traced the 14 grounded-theory categories back 
to the interviews they originated from, thus enabling us to get a better overview of the context of the statements that had provided our categories.

\section{Outcome of the decision-making process: decision quality}

Our study sought to evaluate the decision quality of the IS strategic decisions that were made. To do that, we needed to dive into the raw interview data and analyze the effects of the decisions. Specifically, we analyzed the degree to which those decisions fulfilled the expectations of the decision-makers and others influenced by them, and also how they affected the organization itself. Since decisions are made at both an organizational and an individual level, we had to differentiate between the levels in our analysis.

In the following section we summarize these analytical steps and provide some examples from data to capture the main ideas in each of the decision streams.

\section{Findings}

All the organizations in this study more or less fit an "organizational anarchy" description, at least regarding the processes of IS strategic decision-making. The discussion in this section will spell out the degree to which GCM processes can be recognized and how influential they are in IS strategic decision-making. Further, it will focus on the relationship between user satisfaction and the influence of GCM processes, and the relationship between management commitment and the influence of GCM processes.

\section{Stream of problems}

People first have to identify the problems, or "concerns" (Crecine, 1986), that require attention. Defining problems as "concerns" significantly widens the range of phenomena that can be considered problems. The results of our analysis show that the following grounded-theory categories can be applied to the GCM variable problems:

- Organizational needs

- Degree of formalized communication

- Ability to utilize IT

- IS needs

The four categories all express the respondents' concerns about their organization's IS strategic elements and how it handle those elements. One respondent, a financial mid-level manager in the largest of our entrepreneur corporations, offered us this example: "Even if our accounting system is an accounting system, it doesn't produce reports. We have to extract the information from it and aggregate the data in a spreadsheet. The spreadsheets from our region are passed on to the next level, where data from the different regions are aggregated in a new spreadsheet. We have the same issue in other systems. We should just log on to the system and select the needed reports. It is very time-consuming when we need data that are not in our standard spreadsheets." When asked how they planned to solve this problem, he had no answer. The problem lived its own life, with nobody attempting to solve it. Even though there seemed to be organizational awareness of the problem, it continued its isolated life. A mid-level manager of the archive department in another organization expressed a problem this way: "It's frustrating that our systems have different user interfaces. Different systems have different suppliers and vendors, meaning that we need to have separate logon information and cope with the different user interfaces all the 
time." She explained this problem as resulting from the fact that the decisions to buy the different systems are made at different parts of the organization.

These statements serve as examples of problems the interviewees could identify and that, to use GCM terminology, had not yet been coupled with solutions.

\section{Stream of solutions}

Solutions appear in most of the categories, but only the two below have solutions as their true focus:

- Knowledge of IS strategy

- Future

"Knowledge of IS strategy" is simply about IS strategic decisions that were made and the solutions reflected in those decisions, while "Future" is about how the respondents perceive the future in IS strategic terms. This particular category is very solution-oriented.

One could argue that solutions cannot exist by themselves; they have to be mapped to a problem (Bendor, Moe, \& Shotts, 2001). However, Olsen (2001) notes that Cohen et al.'s (1972) original GC model represents a specific case and that it's only natural that variations of the model's structure will arise in different settings. Most of the solutions identified by the respondents in our study map to one or more problems, at least in a loose way. One respondent said: "That we are now starting to work with Outlook makes me believe that in five years' time we will be there. I also believe we will have more electronic invoicing, which makes it easier for us to store the data in the projects. Now our project groups receive lists every month, and that is the economy management." The statement shows that the solution is coupled with the IT-procurement problem, but because it doesn't receive attention from any participants, no decision can be made. We could provide still other examples from our data showing that individual actors carry with them solutions to problems but have not been able to map them to an available choice opportunity; however, the above statement may suffice as a typical example.

\section{Stream of choice opportunities}

Choice opportunities, or expectations, can be found in many of the categories, but the two below represent the categories with most expectations of IS strategic decisions:

- Strategic process

- Strategically important

The "strategic process" category relates to the perceptions of IS strategic processes, including expectations of the decisions resulting from them, while "strategically important" relates to the perceptions of important ISs for the organization and the expectations of making relevant decisions in that regard. A respondent in the largest of the studied organizations revealed his expectations regarding a possible decision to invest in a Customer Relationship Management (CRM) system: "Yes, it will be brand-new. We don't have a CRM system today. We use Excel spreadsheets for those tasks, but we need structure. Hopefully we can get it soon." In partial summary, our analysis of choice opportunity provides few instances of formal decision-making and resource allocation that made up the original GCM formulation. But our analysis does show that expectations are communicated informally as pressure, norms, and technological possibilities infuse the participant with a sense of urgency for action. 


\section{Stream of participants}

The Garbage Can Model uses two terms to represent participation. The theory differentiates between the participant, which represents the person (who they are), and participation (the act of involvement). Our analysis of the items under participation shows that, following Huber's (1990) prediction, information technology allows for greater participation and thus reshapes the meaning of the concept as it relates to GCM. Our analysis of participation identifies 6 dimensions of participation:

- Management commitment

- User commitment

- User initiatives

- User participation

- Training

- Perceived competence

These items reflect terms of participation. "Management commitment" and "user commitment" refer to participation as involvement, together with training and perceived competence. "User initiatives" and "user participation" refer to the persons participating in the IS strategic decisionmaking processes. The participation spans an entire organization, and instead of a hierarchy of power, it appears to be what Huber (1990) calls a hierarchy of competence.

\section{Decisions as a result of Garbage Can processes}

Although data can identify the streams of problems, solutions, choice opportunities, and participants, those streams do not themselves produce decisions; the decisions result from the many ways they interconnect. Data in this study provide examples of decision-making processes in GCM environments and the resulting decisions.

According to the CIOs, the studied organizations all strive to make rational IS strategic decisions. The data show, however, that they do otherwise. IS strategic decisions as a result of GCM decision-making processes can be found at two different levels. The first may be called the individual level. At that level, the employee experiences problems, knows the solution, and invests energy in applying that solution to the problem. This level was especially evident in the largest of the studied organizations, and typically the problems were related to tasks not solved by the current organizational ISs. Typically, too, the employee invested enough energy to find a satisfactory solution to the problem. As one engineer explained, "The strategy of how to use an information system is not rooted in top management since everyone can do as they please" (referring to all the different systems developed by individuals). But in the highly decentralized structure of the studied organizations, the phenomenon of self-developed information systems seems to be more common the further away, geographically and organizationally, one is located from the company's headquarters.

The second level of IS strategic decisions as a result of GCM decision-making processes, which we'll call the organizational level, covers decisions that affect the whole of, or at least significant parts of, an organization and that involve several people in the decision-making process. Typically these are decisions about buying a new IS and choosing which one is best. Just who participates in the decision process seems to be a coincidence, as the following remark by an economist suggests: "No one gets forced into the project groups; those who wish to participate are allowed to. Then they get their say in developing and exploring the project in question. It is always a very open process, and I believe it is well rooted in management. However, our decentralized organi- 
zation doesn't help, as we don't always get the right people into the projects. That is a challenge in our organization." She points at an important issue in these organizations: there are people who don't get involved in the decision-making process but who should be because of their competence. Table 2 summarizes the two levels of IS strategic GCM decision-making.

\section{Decision quality}

Thus far we have presented only the mechanisms explaining the decision-making process. But decision quality must also be evaluated. Once again, the individual level and the organizational level must be analyzed separately. High-quality IS strategic decisions provide better organizational or individual work performance. Low-quality decisions don't improve organizational or individual work performance and may even degrade either of them.

When individuals in a large organization make decisions independently on IS strategic matters in hopes of finding solutions to problems, those decisions seldom have organizational impact. True, they might now perform certain tasks better, but our data suggest that most of these decisions are low-quality. Even though these individuals sometimes improve their own work performance, they usually don't possess enough IS competence to devise solutions of real IS strategic stature. An engineer provides the following example: "Many people have their own spreadsheets-advanced spreadsheets-and believe that solves everything. When we now introduce a new system, they are really reluctant to accept it. Because of these self-made systems, we are having a hard time getting a strategic value out of the new system." This shows that personal solutions may actually obstruct the IS strategic value from organizational solutions, and hence only be beneficial to one individual, or a small group of individuals, for a limited period of time.

IS strategic decision-making at the organizational level, we found, yields better decision quality and usually has organizational impact. But since many individuals have provided their own solutions to problems of organizational character, implementing the decisions requires substantial effort if they are to be successful.

Table 2 Summary of Garbage Can IS strategic decision-making

\begin{tabular}{|c|c|c|c|c|}
\hline & When & Problems & Solutions & $\begin{array}{l}\text { Decision qual- } \\
\text { ity }\end{array}$ \\
\hline Individual level & $\begin{array}{l}\text { Individuals invest } \\
\text { energy in a problem. } \\
\text { Problem may or } \\
\text { may not concern the } \\
\text { whole organization, } \\
\text { but only the indi- } \\
\text { vidual in question } \\
\text { may benefit from } \\
\text { the solution. }\end{array}$ & $\begin{array}{l}\text { Typically, prob- } \\
\text { lems that current } \\
\text { ISs don't solve or } \\
\text { the individual } \\
\text { doesn't know how } \\
\text { to solve in an exist- } \\
\text { ing IS. }\end{array}$ & $\begin{array}{l}\text { Personal ISs, typi- } \\
\text { cally spreadsheets } \\
\text { or MS Access ap- } \\
\text { plications. Data- } \\
\text { integration prob- } \\
\text { lems with existing } \\
\text { and forthcoming } \\
\text { systems. }\end{array}$ & $\begin{array}{l}\text { Varies. Gener- } \\
\text { ally low for the } \\
\text { organization and } \\
\text { high for an indi- } \\
\text { vidual. }\end{array}$ \\
\hline $\begin{array}{l}\text { Organizational } \\
\text { level }\end{array}$ & $\begin{array}{l}\text { Several individuals, } \\
\text { often project groups, } \\
\text { make IS strategic } \\
\text { decisions. The } \\
\text { whole or large parts } \\
\text { of the organization } \\
\text { may benefit from } \\
\text { the decision. }\end{array}$ & $\begin{array}{l}\text { Bad work flow, } \\
\text { outdated systems. }\end{array}$ & $\begin{array}{l}\text { Implement new or } \\
\text { upgraded ISs. }\end{array}$ & $\begin{array}{l}\text { Generally me- } \\
\text { dium and high } \\
\text { quality. }\end{array}$ \\
\hline
\end{tabular}


The findings in this section form the basis for the following discussion of the results. Our conclusions will then follow.

\section{Discussion and Implications}

The findings show that IS strategic decision-making often happens through GCM processes, and while these processes are hard to control, the decision quality doesn't seem to suffer from it at the organizational level. But when individuals exploit GCMs and make decisions to solve IS strategic issues on their own, the decision quality deteriorates and can even prevent decisions made at the organizational level from being successfully implemented. Furthermore, participation in IS strategic decision-making is very high, probably due to the high density of knowledge workers and to the way modern technology has dramatically increased information flow and opened up a variety of communication channels in organizations (Browning et al., 2006)The fact that the CIOs believe that their organizations have IS strategic-decision processes that follow a rationality scheme (Eisenhardt \& Zbaracki, 1992; Weber, 1947), with no support from data, illustrates how perceptions of one's own agency can be quite delusive.

Our study's major contribution is that it shows that IS strategic issues can be addressed and solved through GCM decision-making processes. But a few challenges arise as a consequence of this. First, we need to focus on the low-quality decisions at the individual level and understand better why these occur. From our data, we cannot find anything to support the inference that the decision-making process (GCM) itself causes these low-quality decisions; rather, the problem seems to lie in their impact area. Whether the phenomenon can be explained by factors like organizational structure, poor management, and/or employee competence remains unclear, but given the "adhocracy lite" structure of the studied organizations, a structural consequence may be less control of employees and hence more freedom for the individual to make decisions (Mintzberg \& McHugh, 1985). Second, the illusion of rationality needs addressing. The decisionmaking process differs from the CIOs' intentions, but still the decision quality is medium/high. It could be that they have failed to institutionalize (Meyer \& Rowan, 1977) these processes, or about managerial perceptions (C. R. Anderson \& Paine, 1975), but we do not rule out other explanations for this phenomenon.

Because only a few organizations served as our case studies here, one should be careful about generalizing to other contexts (Eisenhardt, 1989a; Lee, 1989). But that doesn't mean that similar IS strategic decision-making processes cannot be found in other organizations; indeed, we believe they can be. Still, our research must at this stage be considered as explorative and pertinent only to the IS strategic domain, even though we regard GCM decision-making research in general as a mature field.

For the practice field, this study shows that one should consider mechanisms that either prevent individuals from making IS-strategic decisions not initiated by the organization, or that at least have the ability to control that particular decision-making behavior to avoid low-quality IS strategic decisions. Furthermore, acknowledging that decision-making isn't always a rational process could improve the fit between intended and actual decision-making structures. At last, at the organizational level, GCM decision-making provides sensible IS strategic decisions, meaning that CIOs can focus on implementing the decisions rather than imposing a decision-making rationality that participants do not adapt to.

\section{Future Scope of Research}

Future research should focus on extending investigation to other contexts and in differently structured organizations. Furthermore, research focusing on possible relationships between organiza- 
tional structure and IS strategic decision-making should receive more attention, especially in relation to decision quality. Applying other decision-making theories or frameworks could be a sensible strategy in that regard, as we need to extend our knowledge of how IS strategic decisions are made in different environments and how that affects decision quality. We also need more study to understand why individuals exploit Garbage Cans and try to solve IS strategic issues by themselves even though their doing so tends to yield low organizational benefits.

\section{References}

Anderson, C. R., \& Paine, F. T. (1975). Managerial perceptions and strategic behavior. Academy of Management Journal, 18(4), 811-823.

Anderson, P. A., \& Fischer, G. W. (1986). A Monte Carlo model of a garbage can decision process. In J. G. March \& R. Weissinger-Baylon (Eds.), Ambiguity and command: Organizational perspectives on military decision making (pp. 140-164). Marshfield, MA: Pitman.

Ba, S. L., Stallaert, J., \& Whinston, A. B. (2001). Research commentary: Introducing a third dimension in information systems design - The case for incentive alignment. Information Systems Research, 12(3), 225-239.

Basu, V., Hartono, E., Lederer, A. L., \& Sethi, V. (2002). The impact of organizational commitment, senior management involvement, and team involvement on strategic information systems planning. Information \& Management, 39(6), 513-524.

Bendor, J., Moe, T. M., \& Shotts, K. W. (2001). Recycling the garbage can: An assessment of the research program. American Political Science Review, 95(1), 169-190.

Boynton, A. C., \& Zmud, R. W. (1987). Information technology planning in the 1990s - Directions for practice and research. MIS Quarterly, 11(1), 59-71.

Browning, L. D., Sørnes, J.-O., Stephens, K., \& Sætre, A. S. (2006). A garbage can model of ICT choice. In A. Schorr \& S. Seltmann (Eds.), Changing media markets in Europe and abroad. New ways of handling information and entertainment content. Lengerich: Pabst Science Publishers.

Charmaz, K. (2000). Grounded theory: Objectivist and constructivist methods (2nd ed.). Thousand Oaks, CA: Sage Publications.

Cohen, M. D., \& March, J. G. (1974). Leadership and ambiguity: The American college president. New York, NY: McGraw-Hill.

Cohen, M. D., March, J. G., \& Olsen, J. P. (1972). A garbage can model of organizational choice. Administrative Science Quarterly, 17(1), 1-25.

Crecine, J. P. (1986). Defense resource allocation: Garbage can analysis of procurement. In J. G. March \& R. Weissinger-Baylon (Eds.), Ambiguity and command: Organizational perspectives on military decision making (pp. 72-118). Marshfield, MA: Pittman.

Cutcliffe, J. R. (2000). Methodological issues in grounded theory. Journal of Advanced Nursing, 31(6), 1476-1484.

Earl, M. J. (1993). Experiences in strategic information-systems planning. MIS Quarterly, 17(1), 1-24.

Eisenhardt, K. M. (1989a). Building theories from case-study research. Academy of Management Review, 14(4), 532-550.

Eisenhardt, K. M. (1989b). Making fast strategic decisions in high-velocity environments. Academy of Management Journal, 32(3), 543-576.

Eisenhardt, K. M., \& Zbaracki, M. J. (1992). Strategic decision-making. Strategic Management Journal, 13, 17-37. 
Fardal, H. (2007). ICT Strategy in an ICT user perspective: Exploring alignment between ICT users and managers. Issues in Informing Science and Information Technology, 4, 661-673. Retrieved from http://proceedings.informingscience.org/InSITE2007/IISITv4p661-673Fard362.pdf

Glaser, B. G. (1998). Doing grounded theory. Issues and discussions. Mill Valley, CA: Sociology Press.

Glaser, B. G., \& Strauss, A. (1967). Discovery of grounded theory. Strategies for qualitative research. Mill Valley, CA: Sociology Press.

Golden-Biddle, K., \& Locke, K. (1997). Composing qualitative research. Thousand Oaks, CA: Sage.

Gottschalk, P. (1998). Content characteristics of formal information technology strategy as implementation predictors. Paper presented at the NOKOBIT, Norwegian School of Management, Norway

Gottschalk, P. (1999). Strategic information systems planning: The IT strategy implementation matrix. European Journal of Information Systems, 8(2), 107-118.

Gottschalk, P. (2002). IT-strategi: Fagbokforlaget.

Hayes, S. L., \& McGee, P. B. (1998). "Garbage can decision making" in a "structured anarchy" for your CWIS. Could you translate that for me please? Campus-Wide Information Systems, 15(1), 29-33.

Henderson, J. C., \& Venkatraman, N. (1993). Strategic alignment - Leveraging information technology for transforming organizations. IBM Systems Journal, 32(1), 4-16.

Henderson, J. C., \& Venkatraman, N. (1999). Strategic alignment: Leveraging information technology for transforming organizations. IBM Systems Journal, 38(2-3), 472-484.

Henry, J., \& Stone, R. (1995). A structural equation model of job-performance using a computer-based order entry system. Behavior \& Information Technology, 14(3), 163-173.

Huber, G. P. (1990). A theory of the effects of advanced information technologies on organizational design, intelligence, and decision-making. Academy of Management Review, 15(1), 47-71.

Kanter, R. M. (1988). When a 1000 flowers bloom - Structural, collective, and social conditions for innovation in organization. Research in Organizational Behavior, 10, 169-211.

Lamb, R., \& Kling, R. (2003). Reconceptualizing users as social actors in information systems research. MIS Quarterly, 27(2), 197-235.

Lee, A. S. (1989). A scientific methodology for MIS case studies. MIS Quarterly, 13(1), 33-50.

Levitt, B., \& Nass, C. (1989). The lid on the garbage can - Institutional constraints on decision-making in the technical core of college-text publishers. Administrative Science Quarterly, 34(2), 190-207.

Levy, M., Powell, P., \& Galliers, R. (1999). Assessing information systems strategy development frameworks in SMEs. Information \& Management, 36(5), 247-261.

Lipson, M. (2007). A "garbage can model" of UN peacekeeping. Global Governance: A Review of Multilateralism and International Institutions, 13(1), 79-97.

Locke, K. (2001). Grounded theory in management research: SAGE.

Lofland, J., \& Lofland, L. H. (1994). Analyzing social settings: A guide to qualitative observation and analysis (3rd ed.): Wadsworth Publishing.

Lovata, L. M. (1987). Behavioral theories relating to the design of information-systems. MIS Quarterly, 11(2), 147-149.

Magjuka, R. (1988). Garbage can theory of decision making: A review. Research in the Sociology of Organizations, 6, 225-259.

March, J. G., \& Olsen, J. P. (1984). The new institutionalism organizational factors in political life. Washington, D.C.: American Political Science Review.

March, J. G., Olsen, J. P., \& Christensen, S. (1976). Ambiguity and choice in organizations. Bergen: Universitetsforlaget. 
March, J. G., \& Weissinger-Baylon, R. (1986). Ambiguity and command: Organizational perspectives on military decision making. Marshfield, MA: Pitman.

Masuch, M., \& Lapotin, P. (1989). Beyond garbage cans - an AI model of organizational choice. Administrative Science Quarterly, 34(1), 38-67.

Meyer, J. W., \& Rowan, B. (1977). Institutionalized organizations - Formal-structure as myth and ceremony. American Journal of Sociology, 83(2), 340-363.

Mintzberg, H., \& McHugh, A. (1985). Strategy formation in an adhocracy. Administrative Science Quarterly, 30(2), 160-197.

Newkirk, H. E., \& Lederer, A. L. (2007). The effectiveness of strategic information systems planning for technical resources, personnel resources, and data security in environments of heterogeneity and hostility. Journal of Computer Information Systems, 47(3), 34-44.

Olsen, J. P. (2001). Garbage cans, new institutionalism, and the study of politics. American Political Science Review, 95(1), 191-198.

Padgett, J. F. (1980). Managing garbage can hierarchies. Administrative Science Quarterly, 25(4), 583-604.

Reich, B. H., \& Benbasat, I. (2000). Factors that influence the social dimension of alignment between business and information technology objectives. MIS Quarterly, 24(1), 81-113.

Resnik Mellion, L., \& Moran Tovin, M. (2002). Grounded theory: A qualitative research methodology for physical therapy. Physiotherapy Theory \& Practice, 18(3), 109-120.

Salmela, H., \& Spil, T. A. M. (2002). Dynamic and emergent information systems strategy formulation and implementation. International Journal of Information Management, 22(6), 441-460.

Stenbacka, C. (2001). Qualitative research requires quality concepts of its own. Management Decision, 7(39), 551-555.

Strauss, A. (1978). Negotiations: Varieties, contexts, processes, and social order. San Francisco: Jossey Bass.

Strauss, A., \& Corbin, J. (1990). Basics of qualitative research. Newbury Park, CA: Sage Publications.

Strauss, A., \& Corbin, J. (1994). Grounded theory methodology: An overview. In N. K. Denzin \& Y. S. Lincoln (Eds.), Handbook of qualitative research. London: Sage.

Sørnes, J.-O. (2004). Information and communication technologies in practice - A study of advanced users in the workplace in Norway and the United States. Doctoral Thesis.

Teubner, A. (2006). IT/business alignment. Wirtschaftsinformatik, 48(5), 368-371.

Teubner, A. (2007). Strategic information systems planning: A case study from the financial services industry. Journal of Strategic Information Systems, 16(1), 105-125.

Travica, B., \& Cronin, B. (1995). The Argo - A strategic information-system for group decision-making. International Journal of Information Management, 15(3), 223-236.

Waguespack, D. M. (2006). Reconciling garbage cans and rational actors: Explaining organizational decisions about environmental hazard management. Social Science Research, 35(1), 40-59.

Watson, R. T. (1990). Influences on the IS manager's perceptions of key issues - Information scanning and the relationship with the CEO. MIS Quarterly, 14(2), 217-231.

Weber, M. (1947). The theory of social and economic organization. New York: The Free Press.

Weiner, S. (1976). Participation, deadlines and choice. In J. G. March \& J. P. Olsen (Eds.), Ambiguity and choice in organizations (pp. 225-250). Bergen: Universitetsforlaget. 


\section{Biography}

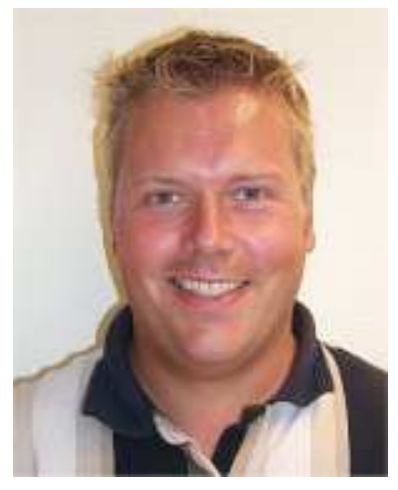

Harald Fardal is a Ph.D. student at Bodø Graduate School of Business, Norway. His research focuses on the processes involved in IT/IS strategy development and in IT/IS projects, and especially on how the competence of end users can strengthen these processes. Fardal also holds an Assistant Professor position at Vestfold University College, where he teaches courses in IS-management. He holds a M.Sc. in information systems from Buskerud University College, Norway.

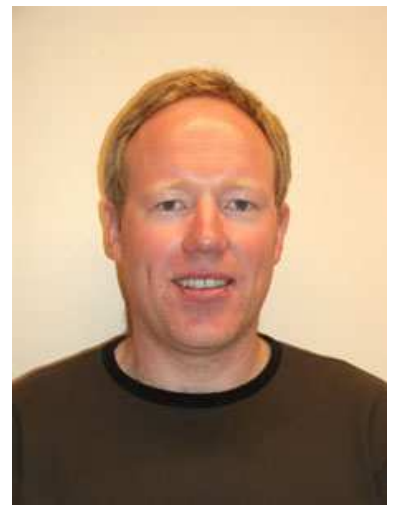

Dr. Jan Oddvar Sørnes is an Associate Professor and Vice Dean at Bodø Graduate School of Business. His research focuses on complexity, organizational communication with focus on ICT, cross cultural communication, decision-making in organizations and energy management. He teaches doctoral courses in qualitative methods and several undergraduate and graduate (MS) courses including Corporate Communication, Energy Management and Organizational Communication with focus on ICTs. 